\title{
French National Health Insurance Information System for Malaria Surveillance
}

\author{
Francois Delon*1, Marc C. Thellier², Aurélie Mayet ${ }^{1}$, Eric Kendjo², Aïssata Dia1, Rémy \\ Michel $^{1}$, Gilles Chatellier ${ }^{3}$ and Guillaume Desjeux ${ }^{4}$
}

${ }^{1}$ Epidemiologic surveillance department, French armed forces Center for epidemiology and public health, Marseille, France; ${ }^{2} \mathrm{French}$ national reference center for malaria, Paris, France; ${ }^{3}$ Department of Clinical Epidemiology, European Hospital Georges Pompidou, Paris, France; ${ }^{4}$ French military health insurance, Toulon, France

\section{Objective}

Estimate the accuracy of the French National Health Insurance Information System (SNIIRAM) as a support for a nationwide malaria surveillance.

\section{Introduction}

The estimated incidence of imported malaria in France is about 4,000 cases per year (1). The epidemiological surveillance o0.f malaria in France is mainly based on a hospital laboratory surveillance network, which captures around $50 \%$ of cases. There is no comprehensive population surveillance. The SNIIRAM provides data about hospital stays and outpatient drug reimbursements, procedures, examinations and sickness leaves for almost the whole French population(2). We aimed to evaluate the usefulness of the SNIIRAM for implementing epidemiological surveillance of malaria.

\section{Methods}

A case-identification algorithm was built in a two-steps process. Firstly, an expert panel defined sensitive inclusion criteria, built using hospital discharge diagnoses, emergency department admissions, outpatient biological procedures and drug deliveries. In case of malaria-nonspecific care events, we considered sequences of events. Secondly, we described data to identify clusters of cases and outliers. Based on this description, we defined exclusion rules, aiming to reduce the number of false-positive and to increase specificity. Results were validated comparing some characteristics of our data with those from the French National Reference Center for Malaria (NRC).

\section{Results}

The algorithm we built was reusable and automated. From July 1, 2013 to June 30, 2014, we identified 4,248 malaria cases corresponding to 4,099 distinct patients (figure 1). The SNIIRAM allowed us to collect data about the demographic characteristics of cases, the date and place of cares, the duration of hospital stays, the diagnoses, the medical procedures and drug deliveries of outpatients. Hospitalization and outpatient drug deliveries data allowed to capture more than $95 \%$ of the cases (table 1). Time-lapse from initial cares to data availability into the SNIIRAM was up to six months.

Our results appeared close to those from NRC: no statistically significant difference was observed in the distribution of age, gender, localization and date at onset.

\section{Conclusions}

We elaborated an accurate algorithm to implement an epidemiological surveillance of malaria based on the French National Health Information System. It allowed to study the population living in France as a whole, including sub-populations not accurately covered by existing surveillance methods. The long latency of the SNIIRAM data availability does not permit early alert. Our approach should be thus considered as an addition to the traditional epidemiological surveillance, though a formal validation framework for case-identification algorithms is still necessary.
Table 1: Distribution of care events among identified malaria cases $(n=4,248)$

\begin{tabular}{|c|c|c|c|c|c|}
\hline \multicolumn{4}{|c|}{ Health Insurance Refund } & \multirow[b]{2}{*}{$\mathrm{n}$} & \multirow[b]{2}{*}{$\%$} \\
\hline Hospitalizations & $\begin{array}{c}\text { Outpatient } \\
\text { Drug Delivery }\end{array}$ & $\begin{array}{c}\text { Laboratory } \\
\text { Tests }\end{array}$ & $\begin{array}{l}\text { Emergency } \\
\text { Department } \\
\text { Admissions }\end{array}$ & & \\
\hline $\mathrm{X}$ & & & & 2,639 & 62.12 \\
\hline $\mathrm{X}$ & $\mathrm{x}$ & & & 136 & 3.20 \\
\hline $\mathrm{X}$ & & $\mathrm{X}$ & & 307 & 7.23 \\
\hline $\mathrm{X}$ & $\mathrm{X}$ & $\mathrm{X}$ & & 48 & 1.13 \\
\hline $\mathrm{X}$ & & & $\mathrm{X}$ & 4 & 0.09 \\
\hline $\mathrm{X}$ & $\mathrm{X}$ & & $\mathrm{X}$ & 13 & 0.31 \\
\hline $\mathrm{X}$ & & $\mathrm{X}$ & $\mathrm{X}$ & 1 & 0.02 \\
\hline \multirow[t]{5}{*}{$\mathrm{X}$} & $\mathrm{X}$ & $\mathrm{X}$ & $\mathrm{X}$ & 9 & .21 \\
\hline & $\mathrm{X}$ & & & 977 & 23.00 \\
\hline & $\mathrm{X}$ & $\mathrm{X}$ & & 75 & 1.77 \\
\hline & $\mathrm{X}$ & & $\mathrm{X}$ & 28 & 0.66 \\
\hline & $\mathrm{X}$ & $\mathrm{X}$ & $\mathrm{X}$ & 11 & 0.26 \\
\hline
\end{tabular}

n: number of cases

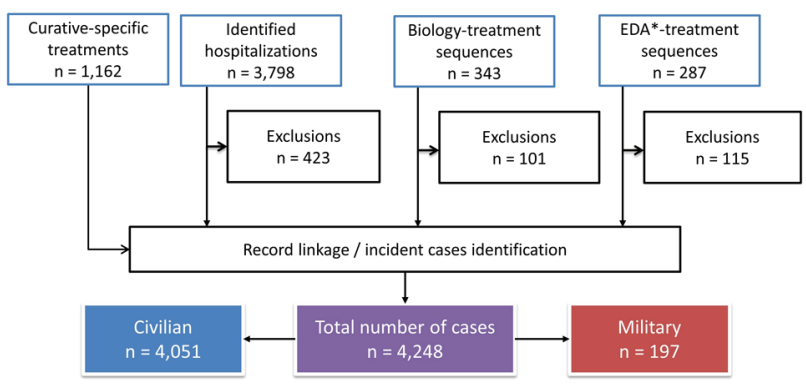

*EDA: Emergency department admission

Figure 1: Flowchart illustrating malaria cases identification

\section{Keywords}

Malaria; Surveillance; Database; Health insurance

\section{Acknowledgments}

This study was supported by the French military health insurance.

\section{References}

1. Rapport annuel d'activité 2013 [Internet]. Centre national de référence du Paludisme; 2014. Available from: http://www.cnrpalu-france.org/ docs/rapport_activites_cnr_paludisme_2013.pdf

2. Tuppin P, de Roquefeuil L, Weill A, Ricordeau P, Merlière Y. French national health insurance information system and the permanent beneficiaries sample. Rev Epidemiol Sante Publique. 2010 Aug:58(4):286-90.

\section{*Francois Delon}

E-mail: francois.delon@laposte.net 